\title{
A importância do laudo pericial médico na formação do entendimento do juízo: análise de casos de suposta má prática médica em cirurgia geral
}

\author{
The importance of medical expert opinion in shaping the \\ understanding of the judge: analysis of claims about medical \\ malpractice in general surgery
}

\author{
Lucas Pedroso Fernandes Ferreira Leal', Antonio Milagres²
}

\begin{abstract}
Leal LPFF; Milagres A. A importância do laudo pericial médico na formação do entendimento do juízo: análise de casos de suposta má prática médica em cirurgia geral.Saúde, Ética \& Justiça. 2012;17(2):82-90.

RESUMO: Atualmente, no Brasil, têm aumentado enormemente as demandas jurídicas impetradas por paciente contra seus médicos. A má prática médica é conceituada como a conduta inadequada, que supõe inobservância técnica, capaz de produzir dano à vida ou agravo à saúde de outrém, mediante imperícia, imprudência ou negligência. A ausência de conhecimento técnico em medicina faz com que a autoridade judicial se utilize da perícia médica para apuração da responsabilidade civil dos envolvidos. O objetivo deste trabalho foi avaliar a importância do laudo pericial médico na formação do entendimento da autoridade judicial em casos de alegada má prática médica na especialidade de cirurgia geral e verificar o impacto da perícia médica na formação de seu convencimento. Estudaram-se os laudos oficiais e as decisões judiciais do ano de 2009 de 100 processos cíveis referentes à má prática médica na especialidade de cirurgia geral, propostas no estado de São Paulo, até a primeira instância. Observaram-se os elementos do laudo pericial e a fundamentação da sentença. Determinaram-se a concordância e a discordância entre os entendimentos médico e jurídico em cada caso. Em todos os julgados mencionou-se a prova pericial médica. Em 96\% dos casos o laudo médico-legal influenciou a decisão judicial. $80 \%$ das sentenças foi desfavorável aos autores. Em $84 \%$ dos casos, o perito não estabeleceu nexo de causalidade. Houve, em $16 \%$ das perícias realizadas, elementos que permitiram concluir pela ocorrência de má prática médica. A concordância deu-se, especificamente, em $75 \%$ quanto à conduta médica inadequada e em $100 \%$ quando se considerou a assistência prestada adequada. Constatou-se que a perícia médica é o principal meio de prova nas ações que versam sobre má prática médica. Demonstrou-se a grande influência do laudo pericial na decisão pela procedência, ou não, das ações. O fornecimento adequado à autoridade competente de esclarecimentos sobre a matéria em tela, com base em conhecimentos científicos, é responsável pela formação do convencimento do magistrado, contribuindo para que se faça justiça.
\end{abstract}

DESCRITORES: Laudo pericial. Exames médicos. Erros médicos. Decisões judiciais. Responsabilidade civil.

\footnotetext{
1. Especialista em Cirurgia Geral e Medicina Legal, Pós-graduado em Medicina Legal e Perícias Médicas - Faculdade de Ciências Médicas da Santa Casa de Misericórdia de São Paulo - FCMSCSP

2. Professor Doutor, Orientador de curso do Departamento de Medicina Legal - Faculdade de Ciências Médicas da Santa Casa de Misericórdia de São Paulo - FCMSCSP

Endereço para correspondência: lucaslealdr@uol.com.br
} 


\section{INTRODUÇÃO}

Os médicos, no exercício de sua profissão, estão sujeitos a três ordens de responsabilidade: a civil, a penal e a ético-profissional. A atividade do médico está sujeita à ampla fiscalização e ao julgamento tanto pelo Poder Judiciário quanto pela estrutura hierárquica dos Conselhos de Medicina (CFM - Conselho Federal de Medicina e CRMs Conselhos Regionais de Medicina) ${ }^{1}$. O tribunal da Justiça comum segue os preceitos dos Códigos Penal e Civil, e o dos Conselhos de Medicina tem seus julgamentos baseados no Código de Ética Médica ${ }^{2}$. Todas as situações denunciadas são apuradas a fim de se fazer justiça ${ }^{3}$. A responsabilidade civil os obriga a ressarcir os prejuízos ocasionados decorrentes da sua conduta e a penal os sujeita à justiça criminal pela prática de delitos tipificados como crime ${ }^{1}$. Os Conselhos, por sua vez, fiscalizam o exercício profissional e julgam as infrações éticas cometidas por médicos que exercem regularmente a profissão no país ${ }^{3}$.

A má prática médica é conceituada como a conduta inadequada, que supõe inobservância técnica, capaz de produzir dano à vida ou agravo à saúde de outrém, mediante imperícia, imprudência ou negligência ${ }^{3}$. Poucos assuntos provocam mais emoção nos médicos do que este tema ${ }^{4}$. Comumente, há referências da ocorrência de "erro médico" quando não se obtém sucesso em procedimento, diagnóstico ou terapêutico, quando a assistência ao doente não se dá de modo que the satisfaça ou quando sua evolução é desfavorável, ainda que inerente à própria condição de saúde ou à prática médica ${ }^{5}$.

A expressão "erro médico" é bastante estigmatizada, seja pela existência de casos específicos, que têm repercussão e visibilidade na mídia, ainda que envolvam outros profissionais não-médicos, seja porque ainda não está claro para a população, de um modo geral, que nem todo mau resultado ou efeito adverso na Medicina esteja necessariamente ligado à má prática médica. Isso, ao longo dos anos, contribuiu para o crescimento quantitativo das denúncias contra médicos que dão entrada na Justiça comum e no Conselho ${ }^{3}$. As profundas mudanças das circunstâncias sociais também podem ser consideradas responsáveis por esta situação. Muitos casos vêm atingindo a classe médica no presente, como o daquele paciente, ou seu familiar, que visa a se beneficiar financeiramente às custas de seu médico, muitas vezes sem ter a consciência da extensão danosa do ato que está cometendo4.
O tratamento médico que não apresente bons resultados, e mesmo aquele cujo resultado obtido não corresponda à expectativa do paciente ou de seus familiares, freqüentemente leva à dúvida se o insucesso foi um mau resultado do procedimento ou decorrente de um erro médico ${ }^{5,6}$. Mesmo com os avanços da ciência e com a crescente incorporação de novas tecnologias, a Medicina ainda não permite que se evitem algumas situações. A ocorrência de um dano, de uma complicação, de uma intercorrência, quase sempre, causa sofrimento ao paciente e seus familiares, o que, aliado a uma relação médicopaciente deteriorada, é responsável por grande parte das denúncias feitas na Justiça Comum e nos Conselhos Regionais de Medicina ${ }^{4,7}$. Contribuem, ainda, para o descontentamento, aumentando tal motivação, a estrutura de atendimento inadequada, a má organização do serviço, os equipamentos precários ou indisponíveis e o investimento insatisfatório em cuidados operacionais essenciais, pelos descaso e descompromisso de autoridades com a saúde, freqüentes na maior parte dos serviços em países subdesenvolvidos ${ }^{3,8,9}$. Também a recente conscientização, cada vez maior, da população em busca de qualidade no atendimento que lhe é oferecido repercute sobre o número de ações judiciais contra os médicos ${ }^{10}$.

Atualmente, no Brasil, apesar de não existirem dados específicos sobre o assunto, têm aumentado enormemente as demandas jurídicas impetradas por paciente contra seus médicos ${ }^{7,10,11}$. As denúncias contra esses profissionais no estado de São Paulo, do mesmo modo, têm crescido progressivamente com o passar dos anos ${ }^{3,12}$. Conforme o registro do Setor de Denúncias do Conselho Regional de Medicina do Estado de São Paulo (CREMESP), no intervalo de $1^{\circ}$ de janeiro de 1994 a 31 de dezembro de 2004, foram protocolados e abertos 24.678 expedientes ${ }^{1}$. Dentre as mais de 3.000 denúncias anuais recebidas pelo CREMESP, cerca de $25 \%$ envolvem supostos atos médicos caracterizados como imperícia, imprudência e negligência do profissional e que podem trazer potencial prejuízo à saúde e à vida do paciente ${ }^{3}$. A especialidade de cirurgia geral assume o terceiro lugar em relação a todas as demandas impetradas contra os médicos, empatada com ortopedia e traumatologia, considerando-se as especificadas nas decisões mais recorrentes referentes a alegado erro médico ${ }^{3,7}$.

A ação cível em que se pleiteia pagamento de indenização por alegado erro médico visa ao ressarcimento dos danos causados ao paciente e/ou 
à sua família em conseqüência do reconhecimento da responsabilidade de um ou mais prestadores de serviço de saúde ${ }^{5,13}$. O montante em dinheiro, se concedido, geralmente leva em conta tanto a perda econômica material real quanto a não-econômica, moral, tais como dor e sofrimento ${ }^{14}$. A compensação financeira do indivíduo que, de fato, foi vítima de má prática médica é importante ${ }^{15}$, sendo ainda mais relevante quando utilizada para lidar com a sua saúde ${ }^{16}$. Uma vez restando reconhecida a responsabilidade, será fixada alguma condenação. Há necessidade, desta maneira, de comprovação da existência de culpa. A ausência de conhecimento técnico em medicina faz com que a autoridade judicial se utilize da perícia médica, na maioria dos casos, para apuração da responsabilidade civil dos envolvidos, da ocorrência e da extensão do dano alegado e da existência do nexo de causalidade entre a conduta médica e tal dano.

A perícia médica é o principal meio de prova nas ações que versam sobre má prática médica. $O$ fornecimento adequado à autoridade competente de esclarecimentos sobre a matéria em tela, com base em conhecimentos científicos, é responsável pela formação do convencimento do juízo. Outros meios de prova também são utilizados, como depoimento testemunhal e documentos escritos, mas o relatório pericial é o precípuo subsídio que auxilia o juízo em sua decisão. Ainda que o julgador não possa se imiscuir nas apreciações de ordem técnica quanto aos meios utilizados e à evolução clínica apresentada, dentre outras circunstâncias as quais são alvo de discussões mesmo entre profissionais especializados, o magistrado não está adstrito ao relatório médico-legal. Em alguns casos, o laudo pericial pode não ser capaz, todavia, de fazer entender aspectos envolvidos no exercício da medicina, a natureza da doença e a complexa estrutura biopsicossocial dos indivíduos. As decisões judiciais não devem separar lei e ciência, que possuem fronteiras comuns, de modo que o poder judiciário possa melhor fazer justiça em condições de incerteza e de ignorância ${ }^{17}$.

Neste contexto, é necessário avaliar a importância do laudo pericial médico na formação do entendimento do magistrado em casos em que se pleiteia indenização por suposto "erro médico". A análise do posicionamento do juízo e da fundamentação das sentenças proferidas, em ações judiciais relacionadas à especialidade de cirurgia geral, impetradas no estado de São Paulo, frente ao que se constata numa perícia médica, permite verificar as bases do entendimento do julgador no contencioso desta natureza tanto quanto a influência do laudo pericial na procedência, ou não, da ação. Tem-se que o esclarecimento técnico de pontos controvertidos, o fornecimento de elementos que subsidiem a convicção judicial, cumprindo o laudo pericial o fim a que se destina, contribui para que se faça Justiça.

\section{OBJETIVOS}

\section{Geral}

Avaliar a importância do laudo pericial médico na formação do entendimento da autoridade judicial em casos de alegada má prática médica na especialidade de cirurgia geral.

\section{Específicos}

- Verificar o impacto da perícia médica na formação do convencimento do magistrado em primeira instância;

- identificar a concordância entre o entendimento pericial médico e a convicção do juízo;

- analisar o posicionamento da autoridade judiciária diante da conclusão pericial em reclamações cíveis que versam sobre o atendimento prestado por cirurgião geral;

- averiguar os principais fundamentos que embasaram as decisões judiciais em processos em que se pleiteia indenização por suposta má prática médica na especialidade de cirurgia geral.

\section{MATERIAL E MÉTODO}

Realizou-se levantamento de 100 processos cíveis que versavam sobre má prática médica na especialidade de cirurgia geral, cujos laudos médicos periciais foram concluídos no ano de 2009. As ações cíveis selecionadas dizem respeito às propostas perante a Justiça estadual de São Paulo, em que se designou o IMESC - Instituto de Medicina Social e de Criminologia do Estado de São Paulo, autarquia vinculada à Secretaria da Justiça, para a produção da prova técnica. Utilizaram-se casos consecutivos avaliados por um mesmo perito oficial, após aprovação do corpo diretivo da instituição.

$\mathrm{O}$ andamento processual e as sentenças de cada caso foram consultados na internet, mediante acesso ao site do Tribunal de Justiça do Estado de São Paulo - www.tj.sp.gov.br. O estudo retrospectivo englobou apenas as decisões proferidas em primeira instância. Não foram consideradas na presente pesquisa as decisões 
que foram objeto de recurso por qualquer uma das partes envolvidas.

Criou-se um banco de dados, no qual foram relacionados o número interno da respectiva pasta no IMESC, a data da realização da perícia médica, a data da expedição do laudo, a data da sentença, a conclusão pericial e a decisão judicial. Observaram-se os elementos do relatório médico-legal e a fundamentação da sentença. Estabeleceu-se correlação positiva ou negativa entre a conclusão do perito e o convencimento do magistrado. Verificaram-se as incidências da concordância e da discordância entre os entendimentos médico e jurídico em cada caso, sob a óptica médico-legal. Na sequência, foram avaliados e discutidos os relevantes aspectos periciais e doutrinários que embasaram a sentença, ensejando ou não o reconhecimento de responsabilidade civil do médico.

Utilizando-se as bases de dados PUBMED (National Center for Biotechnology Information, National Library of Medicine, National Institutes of Health) e SCIELO (Scientific Eletronic Library Online), através dos endereços eletrônicos da internet http://www.pubmed.org e http://www. scielo.br, foi realizada pesquisa bibliográfica sobre a condenação judicial por reconhecida má prática médica e sua relação com as conclusões dos laudos periciais, a fim de se poder fazer uma revisão da literatura a respeito do tema. As seguintes palavras-chave foram utilizadas: medical malpractice, judicial, claim, surgery, abdominal surgery, judgement, expert, em diferentes combinações. Foram selecionados artigos que satisfizeram os seguintes critérios de inclusão: idioma do texto - inglês ou espanhol, ano de publicação - entre 1990 e 2011, material - textos na íntegra, tema - influência do laudo pericial médico em demandas judiciais, e relacionados. Livros-texto sobre a matéria médico-legal também foram consultados.

\section{RESULTADOS}

Foram coletadas e analisadas 25 decisões proferidas pela Justiça do Estado de São Paulo, em primeira instância, a partir da amostra selecionada de 100 ações cíveis, que cuidavam de aspectos referentes à responsabilidade do médico de indenizar o autor, seja o próprio paciente ou indivíduo de sua família. $\mathrm{O}$ andamento processual de três casos não pôde ser consultado mediante acesso ao site do tribunal por motivos de 'segredo de justiça'. Setenta e duas causas encontravamse, ainda, em fase de oitiva de testemunhas, apresentação de memoriais, expedição de ofício, aguardando redesignação de audiência e conclusos para análise do magistrado.

Em nenhum dos julgados se deixou de mencionar a prova pericial médica. Em todos os casos os julgadores demonstraram a base técnica que fundamentou os julgamentos. Verificou-se que em 24 das 25 sentenças analisadas (96\%), o laudo médico-legal influenciou de modo significativo a decisão judicial. Observou-se discordância entre o entendimento judicial e a constatação pericial em apenas 01 caso (04\%). Em 21 dos 25 casos (84\%), o perito não constatou nexo entre as alegações de má prática médica e o que se verificou na perícia. Encontraram-se, em 04 das 25 perícias realizadas (16\%), elementos que pudessem qualificar má prática médica, ao passo que o entendimento do julgador foi neste sentido em apenas 03 casos (12\%). A concordância deu-se numa ordem de $75 \%$ em relação à conduta médica que foi considerada inadequada (03/04) e em 100\% (21/21) nos casos em que se considerou a assistência prestada de acordo com o preconizado, não se estabelecendo nexo de causalidade.

Naamostra das decisões judiciais integrantes da presente análise, houve condenação em 05 dos 25 (20\%) processos analisados. As ações foram julgadas totalmente procedentes em 08\% dos casos, e procedentes em parte em $12 \%$. Os 03 médicos que foram condenados a ressarcir os autores tiveram a responsabilidade dividida com o hospital ou com a seguradora de saúde (solidária). Nos outros 02 casos julgados procedentes, foram responsabilizados num o Hospital e noutro o Estado. Os demais profissionais processados foram absolvidos (88\%).

A tabela abaixo representa o banco de dados criado com o número interno de cada pasta do IMESC, correspondente a um processo cível que versa sobre má prática médica em cirurgia geral. Verificam-se a existência, ou não, de elementos sugestivos de falha assistencial, de acordo com o respectivo laudo pericial e o entendimento do juiz quanto à ocorrência de qualquer das modalidades de culpa médica e/ou determinação de indenização; observa-se a citação da prova técnica na fundamentação da sentença judicial; e obtém-se a correlação positiva ou negativa estabelecida, de acordo com o convencimento do magistrado, à luz do que demonstrou e esclareceu o perito. 
Leal LPFF; Milagres A. A importância do laudo pericial médico na formação do entendimento do juízo.

TABELA1 - Impacto do conteúdo do laudo oficial na fundamentação da decisão judicial

\begin{tabular}{|c|c|c|c|c|c|c|}
\hline \multicolumn{7}{|c|}{} \\
\hline
\end{tabular}

Legenda: Perito - entendimento pericial para elementos que possam configurar má prática médica. Juiz - convicção do magistrado sobre a ocorrência de má prática médica. Relação - Concordância entre o entendimento pericial e a decisão do julgador. (+) /(-) - Positivo ou Negativo para a ocorrência de 'má prática médica', em "Perito" e "Juiz", e para a concordância entre os respectivos entendimentos, em "Relação".

\section{DISCUSSÃO}

Analisando o entendimento da autoridade judiciária pelo laudo pericial médico em ações propostas contra profissionais, em que se pleiteia indenização por suposta má prática no exercício da medicina, verificou-se o impacto da prova técnica na formação de sua convicção, influenciando sobremaneira cada decisão. Em todas as sentenças publicadas, os julgadores registraram expressamente a realização da perícia médica. As decisões judiciais foram fundamentadas mencionando o que se fez entender da prova pericial. Conteúdos do relatório médico foram transcritos na maioria dos casos.

Tem-se que em 96\% das decisões judiciais
(24/25), o laudo médico-legal foi a base do entendimento dos magistrados. A casuística apresentada pela pesquisa feita pelo CREMESP ratifica esses achados ${ }^{3}$. Houve discordância em apenas 01 caso da presente casuística; não fosse por isso, a influência seria absoluta. Supreendentemente, não obstante houvesse elementos apontados no laudo pericial que permitissem concluir pela ocorrência de má prática médica, o entendimento judicial deu-se de modo absolutamente contrário à constatação pericial, absolvendo-se o médico-réu.

Insta aduzir que no processo cuja respectiva pasta recebeu o número 202.463, interessantemente, verificou-se que o juízo não compreendeu a conclusão pericial; daí o 
Leal LPFF; Milagres A. A importância do laudo pericial médico na formação do entendimento do juízo.

posicionamento dissonante. Não foi o caso de divergência justificada, que é prevista no Direito. Afirmar que a autoridade judicial se equivocou não é abusivo. Houve, de fato, falha no entendimento da prova técnica. Revisando o laudo oficial, observouse que os elementos necessários para a conclusão foram devidamente expostos. Entretanto, a fundamentação da sentença foi de encontro ao que foi explanado pelo perito oficial. Vejamos:

Ajuizou-se a ação contra a Fazenda Pública do Estado de São Paulo, alegando a autora que era obesa e que preencheu lista de espera para realização de cirurgia bariátrica em hospital estadual, sendo que embora tenha sido submetida a um procedimento cirúrgico, decorridos poucos meses constatou-se que a cirurgia bariátrica não foi realizada. Pleitearam-se danos morais e pagamento de despesas em hospital particular para ser submetida à cirurgia devida. No relatório da perícia médica, após explicações sobre a doença 'obesidade', suas comorbidades, critérios de indicação de tratamento cirúrgico e quais os respectivos procedimentos aprovados pelo Conselho Federal de Medicina, o perito concluiu, claramente: " $A$ pericianda, à época dos fatos, tinha indicação de tratamento cirúrgico da obesidade mórbida. A pericianda não foi submetida à cirurgia de Fobi-Capella (cirurgia bariátrica que Ihe seria indicada). A pericianda foi submetida à cirurgia de derivação jejuno-ileal. A pericianda tem, na presente data, indicação de realização de cirurgia bariátrica". No item "Discussão" do laudo pericial constam os procedimentos cirúrgicos que são aceitos no país para o tratamento da obesidade mórbida, os critérios de escolha de cada intervenção, com explicações em termos leigos, e a derivação jejuno-ileal não foi listada entre eles. Também não se realizou a cirurgia de Payne - a qual, por suas consequências, foi proscrita - mas tão somente uma anastomose jejuno-ileal, sem desvio de trânsito. Tal 'derivação', do modo como foi feita, não é, nem nunca foi, considerada uma intervenção bariátrica. É certo que a pericianda se submeteu a um ato cirúrgico, com riscos, inadequado, e que não é descrito para esse fim. $\mathrm{O}$ espirt de corps talvez tenha feito com que o perito não criticasse com veemência essa conduta esdrúxula e abominável, mas deixando o juízo se aperceber do que se sucedeu, com tudo o que foi exposto e discutido. A magistrada publicou: "A pretensão não merece acolhida porque a prova pericial dos autos comprova que a autora foi, sim, submetida a uma das modalidades de cirurgias bariátricas, qual seja, cirurgia de derivação jejunoileal. Em sendo a causa de pedir a não realização de cirurgia bariátrica e em havendo prova inequívoca de que a paciente foi, sim, submetida a um dos tipos de tal cirurgia, patente a improcedência da demanda. A circunstância de haver ainda, nos dias atuais, indicação de realização de cirurgia bariátrica em nada socorre a autora, já que a causa de pedir é a não realização da cirurgia e não a realização de cirurgia equivocada ou necessidade de novo procedimento cirúrgico". Julgou-se a ação improcedente. Discordamos da decisão judicial, sob a óptica médico-legal, ainda que exorbite nossa competência. Como no universo desta pesquisa analisamos tão somente as decisões de 1a instância, não dispomos de maiores informações sobre eventuais embargos de sentença ou então a reforma pelo tribunal.

Mister registrar que, especificamente, a concordância foi verificada em 100\% (21/21) dos casos em que se considerou adequada a assistência médica prestada. Em que pese a discordância verificada no caso exposto, quando o entendimento judicial se fez no sentido da ocorrência de falha assistencial, pela observação das evidências demonstradas no laudo pericial, impôs-se condenação aos réus. Uma vez caracterizado o dano e estabelecido o nexo de causalidade, julgando-se a conduta culposa, há condenação do médico. Independentemente da imposição ou não de condenação, na fundamentação de todas as sentenças - onde o juízo explicita o entendimento que lhe permite decidir - se registrou o teor do laudo oficial.

Sabe-se que a opinião do perito não vincula a do juiz. A autoridade judicial não fica adstrita ao laudo médico, podendo discordar, no todo ou em parte, das suas conclusões, e determinar a realização de nova perícia, se assim julgar conveniente. Pode haver casos, embora mais raros, em que o juiz, analisando a perícia junto às demais provas constantes do processo, decida em sentido oposto ao laudo pericial. Assim prevê a legislação ${ }^{2,18-21}$. Mas como se pode constatar, apesar de a convicção do magistrado não estar total nem absolutamente vinculada ao resultado da perícia médica, sua influência na formação do convencimento do juiz é substancial.

De fato, há dificuldade para o leigo em medicina apurar a existência de elementos que possam configurar a má prática médica, pela complexidade técnica envolvida em determinadas situações. Notória a influência de aspectos relacionados às condições de saúde do indivíduo envolvido, do ambiente, da situação, dos riscos inerentes a qualquer ato médico, e da evolução da própria afecção de saúde na recuperação de alguma medida intervencionista, com fins terapêuticos, por 
exemplo. O reconhecimento da efetiva relação entre a conduta do profissional e o dano alegado, às vezes inevitável ou inexistente, é de exclusiva competência pericial.

Nessa amostra, das 05 ações que foram julgadas procedentes (20\%), apenas em 03 o profissional médico litisdenunciado teve a responsabilidade civil reconhecida, a qual foi solidária com os co-réus Hospital e Seguradora. Isso se deve à demonstração da existência de nexo de causalidade entre o que se verificou na perícia e a conduta médica em tela, entendida pelos magistrados como culposa, fundamental para se atribuir a obrigação de indenizar. O princípio adotado na condenação dos profissionais a ressarcir os danos verificados foi 0 da responsabilidade subjetiva. Evidências das três modalidades de culpa foram verificadas em todos os casos. Independentemente dessa discriminação, o que às vezes pode ser difícil de se realizar, ainda mais com o entendimento judicial, ocasionalmente diverso em termos conceituais, e que não tem qualquer implicação jurídica para a configuração da responsabilidade subjetiva nem sobre o grau da condenação, é o precípuo fim da perícia médica caracterizar o dano e o nexo causal com a conduta profissional.

Nos outros 02 casos, houve condenação tão somente do Estado, do Hospital e da Seguradora, em virtude de danos morais, ainda que não se tenha configurado a mala praxis, considerando-se a teoria da responsabilidade objetiva desses sucumbentes, em que basta o nexo de causalidade, independente da ausência de culpa no agir dos médicos. Há nítida divisão da Justiça quanto a essa natureza. Ademais, a falta de evidências para se caracterizar a má prática médica não é incomum ${ }^{(22)}$.

A maioria das decisões (80\%) foi, portanto, desfavorável aos autores, julgada improcedente. Não fosse o discutido entendimento judicial - ou o brando e polido esclarecimento pericial - o índice seria menor (76\%). A conclusão do perito foi pela existência de má prática médica na minoria dos casos (16\%). Os dois principais fundamentos dos magistrados para não reconhecer o direito pleiteado, declarando isentos de responsabilidade os profissionais sub judice, nos casos analisados, foram a falta de comprovação da culpa e a ausência de demonstração do nexo de causa e efeito. Resultados semelhantes foram apresentados em nosso meio na publicação do $\mathrm{CREMESP}^{3}$. E não é só neste país que há elevada percentagem de alegações equivocadas ${ }^{23,25}$, que geram custos exorbitantes ${ }^{22,26}$.

Em verdade, para caracterização da responsabilidade civil do médico é imprescindível o estabelecimento do nexo de causalidade entre os efeitos de seusatos ou omissões eos danosalegados pelos autores. Eis que não basta simplesmente alegar o suposto "erro médico"; é fundamental que se demonstre, de forma clara e objetiva não só o dano, mas, principalmente, o nexo de causalidade entre a conduta do réu e o que foi verificado na perícia médica. Diante da falta de requisitos para se caracterizar a má prática, não se impõe qualquer responsabilização; ausente a comprovação de ato culposo ou dano secundário, afasta-se a pretensão indenizatória. A demonstração da existência, ou não, do nexo causal entre as condutas médicas e o que é constatado na perícia médica, fornecendo elementos para a caracterização, ou não, de culpa, meritoriamente, dentre outros esclarecimentos teóricos sobre a matéria em tela é a incumbência pericial, como se expôs inicialmente.

Acreditamos que mesmo dispondo de uma maior amostragem de reclamações impetradas na justiça cível contra médicos para análise, os percentuais seriam semelhantes aos observados nesta pesquisa, tendendo ao publicado em relação ao estado de São Paulo $^{3}$. Ainda que o juízo não esteja adstrito ao laudo pericial, tem-se que é extremamente significativa sua influência na formação de suas convicções, desde que a prova técnica de natureza médica lhe seja útil, fornecendo os subsídios necessários para configurar, ou não, o dever de indenizar. Só pode servir bem à justiça o perito que for completo, metódico, minucioso, sem idéias ou hipóteses preconcebidas, atendendo às necessidades da autoridade judiciária ${ }^{2,21,24}$, no equilíbrio entre a redação técnica e o fornecimento de informações às vezes quase que coloquial, não se podendo admitir um modelo separatista entre a lei e a ciência.

A importância da perícia médica reside no sentido de estender o olhar dos magistrados, permitindo a justiça social, para muito mais além do que um desfecho desfavorável. A prestação de serviços de saúde se dá de forma complexa, sem compromisso de resultado, envolvendo, muitas vezes, vários médicos, de especialidades distintas, e outros profissionais da área. Há que se considerar toda uma constelação de fatores, numa complexa interação, que envolve o restabelecimento da saúde: fatores endógenos, psicológicos, próprios da doença, dentre os mais variados, podem contribuir para um evento indesejado, independentemente das medidas usuais e dos meios empregados, de acordo com a particularidade de cada indivíduo. Com efeito, não se pode culpar o profissional se as consequências dos cuidados ou do tratamento 
por ele prescritos fogem de seu total controle, a depender da resposta e do funcionamento de cada organismo, o que é muito particular e está além dos conhecimentos e do alcance da mente humana. Ademais, a imperfeição da ciência é uma realidade com a qual se convive. O julgamento justo consistente em provas, incluindo, especialmente, a de natureza técnica, além de argumentos concisos - finda quando resta evidenciado ter havido má prática médica, ou não, do modo devido.

\section{CONCLUSÕES}

A perícia médica é a prova técnica, de conhecimento médico fático-científico, que fornece subsídios essenciais para a decisão judicial em casos de alegada má prática médica, determinando o entendimento do juízo de modo substancial. A prova pericial é de grande valia, na maioria das vezes, para a formação do entendimento do julgador, que não dispõe de conhecimentos suficientes a respeito da matéria médica. As conclusões do julgador, pela fundamentação das decisões, são influenciadas pelos elementos e esclarecimentos que lhe são fornecidos no relatório médico-legal.
Nossa casuística demonstra a grande relevância do laudo pericial na procedência, ou não, das reclamações ajuizadas contra médicos, interferindo sobremaneira no desfecho da lide.

A sentença é uma peça de inteligência que se baseia em todas as provas pertinentes apresentadas e no previsto pelas doutrina, legislação e jurisprudência, conforme a convicção do magistrado. Algumas conclusões e observações do perito podem ser aceitas e outras desconsideradas, visto que o resultado da perícia não vincula o entendimento do juízo. O julgador acompanha as considerações médico-legais elaboradas pelo experto na maioria dos casos. O princípio invocado na imposição de condenação dos médicos, que se dá com menor frequência, em todos os casos desta pesquisa, é o da responsabilidade subjetiva - necessário o estabelecimento do nexo de causalidade entre os efeitos de seus atos ou omissões e os danos alegados pelos autores, caracterizando-se a conduta culposa. Ainda que se demonstre a ausência de falha na assistência à saúde, o magistrado pode impor condenação ao outro réu, não médico, considerandose a natureza objetiva de sua responsabilidade, em que prescinde a culpa.

Leal LPFF; Milagres A. The importance of medical expert opinion in shaping the understanding of the judge: analysis of claims about medical malpractice in general surgery. Saúde, Ética \& Justiça. 2012;17(2):82-90.

\begin{abstract}
Currently, in Brazil, legal demands filed by patients against their doctors have enormously increased. Medical malpractice is defined as improper conduct, which involves a technical failure, capable of producing damage to life or harm to health of others. The lack of expertise in medicine makes the judicial authority require an expert opinion to determine the liability of those involved. The aim of this study was to assess the importance of medical expert opinion in shaping the understanding of judges in cases of alleged medical malpractice in general surgery and to evaluate the impact of medical expertise in the formation of his decision. We have studied the official forensic reports and court decisions of the year 2009 of 100 civil cases related to medical malpractice in general surgery, proposed in the state of São Paulo, in first instance. We have observed elements of the expert report and the reasons for the sentence. We have determined agreement and disagreement between the medical and legal understandings in each case. In all decisions judges have mentioned the forensic evidence exposed by the expert. In $96 \%$ of cases the forensic report influenced the decision. $80 \%$ of the sentences were unfavorable to the authors. In $84 \%$ of cases, the expert did not establish the cause-effect relationship. In $16 \%$, elements related to medical malpractice were well qualified. The agreement took place, specifically, in $75 \%$ for the inadequate medical management and $100 \%$ when the expert considered the assistance appropriate. Thus, medical examination with expert opinion is the primary means of proof in actions that deal with medical malpractice. The results confirm the strong influence of expert opinion in the merits or otherwise of the actions. The adequate supply to the competent authority for clarification on the matter at hand, based on scientific knowledge, is responsible for the formation of the magistrate's conviction, contributing to justice.
\end{abstract}

KEYWORDS: Medical expert opinion. Medical malpractice. Judgement. Liability.

\title{
REFERÊNCIAS
}

1. Boyaciyan K, Camano L. O perfil dos médicos denunciados que exercem ginecologia e obstetrícia no estado de São Paulo. Rev Assoc Med Bras 2006; 52(3): 144-7. 
2. França GV. Medicina legal. 8ª ed. Rio de Janeiro: Guanabara-Koogan; 2008.

3. Conselho Regional de Medicina do Estado de São Paulo. O médico e a justiça: um estudo sobre ações judiciais relacionadas ao exercício profissional da medicina. São Paulo: CREMESP; 2006. 92 p.

4. Dove JT, Brush JE Jr, Chazal RA, Oetgen WJ. Medical professional liability and health care system reform. J Am Coll Cardiol. 2010 Jun 22;55(25):2801-3.

5. Giostri HT. Erro médico à luz da jurisprudência comentada. 2a ed. rev. 5 ${ }^{\underline{a}}$ tir. Curitiba: Juruá; 2008. $432 \mathrm{p}$.

6. Ferraz EM. Complicação ou erro médico? Rev Col Bras Cir 2006. 33(4): 205-6.

7. Bitencourt AVG, Neves NMBC, Neves FBCS, ISPS Brasil, LSC Santos. Análise do erro médico em processos ético-profissionais: implicações na educação médica. Ver Bras Educ Med 2007; 31(3): 223-8.

8. Edwards IR. The WHO world alliance for patient safety: a new challenge or an old one neglected? Drug Saf. 2005; 28(5): 379-86.

9. Arenas-Márquez $\mathrm{H}$, Anaya-Prado R. Errors in surgery. Strategies to improve surgical safety. Cir Cir. 2008 Jul-Aug;76(4):355-61.

10. Godinho AM, Lanziotti LH, Morais BS. Informed consent: the understanding of lawyers and courts. Rev Bras Anestesiol 2010; 60: 2: 207-214.

11. Souza NTC. Responsabilidade civil no erro médico. (monografia em Cd-Rom). Porto Alegre: Direito Médico; 2001.

12. Conselho Regional de Medicina do Estado De São Paulo. Ética em ginecologia e obstetrícia. $3^{\underline{a}}$ ed. São Paulo: CREMESP; 2004.

13. Souza NTC. Responsabilidade civil e penal do médico. Campinas: LZN Editora; 2003.

14. Bal BS. The expert witness in medical malpractice litigation. Clin Orthop Relat Res. 2009 Feb;467(2):38391.

15. Davis P, Lay-Yee R, Fitzjohn J, Hider P, Briant R, Schug S. Compensation for medical injury in New Zealand: does "no-fault" increase the level of claims making and reduce social and clinical selectivity? J Health Polit Policy Law. 2002 Oct;27(5):833-54.

16. Wood C. The misplace of litigation in medical practice. Aust N Z J Obstet Gynaecol. 1998 Nov;38(4):365-76.

17. Jasanoff S. Law's knowledge: science for justice in legal settings. Am J Public Health. 2005;95 Suppl 1:S49-58.

18. Diniz MH. Curso de direito civil brasileiro. Responsabilidade civil. 19a ed. São Paulo: ERT; 2005. 7 vol.

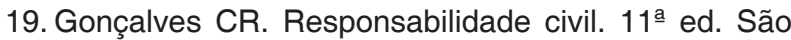
Paulo: Saraiva; 2009.

20. Breda J. Responsabilidade civil do médico. $2^{\underline{a}}$ ed. São Paulo: Brasbiblos; 1997.

21. Kfouri Neto M. Responsabilidade civil do médico. $3^{\text {a }}$ ed. São Paulo: Ed. Revista de Tribunais; 1999.

22.Studdert DM, Mello MM, Gawande AA, Gandhi TK, Kachalia A, Yoon C, et al. Claims, errors, and compensation payments in medical malpractice litigation. N Engl J Med. 2006 May 11;354(19):2024-33.

23. B-Lynch C, Coker A, Dua JA. A clinical analysis of 500 medico-legal claims evaluating the causes and assessing the potential benefit of alternative dispute resolution. $\mathrm{Br} \mathrm{J}$ Obstet Gynaecol. 1996 Dec;103(12):1236-42.

24. Kluge R, Koob R. Expert assessment of medical malpractice. Orthopade. $2001 \mathrm{Feb} ; 30(2): 117-20$.

25. Schwab S, Streuli R. Extrajudicial expert assessment-what is the basis for complaints against internists? Praxis (Bern 1994). 1999 Nov 25;88(48):1981-93.

26. Traina $F$ Medical malpractice: the experience in Italy. Clin Orthop Relat Res. 2009 Feb;467(2):434-42. 